\title{
A Proposed Model for Detecting Facebook News' Credibility
}

\author{
Amira M. Idrees ${ }^{1}$, Fahad Kamal Alsheref ${ }^{2}$, Ahmed I. ElSeddawy ${ }^{3}$ \\ Information Systems Department, Faculty of Computers and Information, Fayoum University, Egypt ${ }^{1}$ \\ Information Systems Department, Faculty of Computers and Information, Beni-Suef University, Egypt ${ }^{2}$ \\ Arab Academy for Science, Technology and Maritime Transport, Egypt ${ }^{3}$
}

\begin{abstract}
Social networks are currently one of the main News' sources for most of their users. Moreover, News channels also consider social networks as main channels not only for spreading the news but also for measuring the feedback from their followers. Facebook Followers can comment or react to the news, which represents the follower's feedback about this topic. Therefore, it is a fact that measuring the News' credibility is one of the important tasks that could control the propagation of the fake news as well as the number of News' followers. The proposed model in this research highlights the impact of the News' followers on detecting the News' polarity either it is fake or not. The proposed model focuses on applying an intelligent sentiment analysis using Vector Space Model (VSM) which is one of the most successful techniques on the users' comments and reactions through the emoji. Then the degree of credibility is determined according to the correlation coefficient. An experimental study was applied using Facebook News dataset, which included the News and the followers' feedbacks.
\end{abstract}

Keywords-Social network; vector space model; correlation coefficient; sentiment analysis

\section{INTRODUCTION}

Earning experiences from colleagues and friends has been considered long time ago [1] [2] [3] by different methods, however, a focus on social media source is recently highlighted. Considering applying mining techniques in different fields to support text analysis as well as emotion analysis has been proposed by different research such as in [4] [5] [6] and in [7]. The popularity of Social Networks are continuously increasing not only from population but it is also considered as a main resource to formal News' institutes. This population has led to a continuous focus from a large number of researchers [8], [9] [10]. Specifically, Facebook has a leading position among other social networks [11]. One of the main popular features in Facebook is the ability to express and share a reaction by different methods either by text, image, emoji, and others as well as the ability to control the privileges of others on this reaction. However, users may share fake news with no intention as they have no way to measure its credibility while they may become one of the main resources of credibility detection [12] [13]. Therefore, many research have been proposed for detecting the posts' polarity [9] as well as the fake news [14] [15].

Focusing on Facebook, different situations may be highlighted, the users' contribution may be not relevant to the post or a spam [13] [16]. Therefore, focusing on different users' response such as comments and emotions is considered one of the success factors for measuring credibility [17] [18]. The proposed model in this research considers detecting the credibility according to the comments and emotions analysis.

The remaining of this paper is organized as follows. Section 2 provides the technical background that is used in the rest of the paper. Section 3 defines our proposed model and the modifications that had been done on the original one. Section 4 studies our methods in a case study. Finally, Section 5 contains the conclusion and future work.

\section{BACKGROUND}

There are several definitions and techniques used in the proposed model. Each one used for a specific purpose identified in section IV. These definitions and techniques are:

- Facebook reactions and their polarity [17] [8] [9].

- Vector space model: for measuring the text similarity between the post and comments on this post [19] [20].

- Sentiment analysis: for measuring the polarity of the comments on the tested post [21].

- Correlation coefficient: for measuring the convergence between the result from Facebook emotions and the analysis of post [21] [22].

\section{A. Facebook Reactions}

Facebook released the ability to respond by emotions in February 2016 additionally to the like emotion. Currently, six emotions are available to express the users' reaction represented in figure 1, they are as follows [23]:

a) Like: represents liking of the proposed post or comment.

b) Love: represents more than liking and express more empathy about the post.

c) Wow: represents surprising feeling that the post expresses unexpected act or event.

d) Haha: represents a funny reaction like irony or laugh.

e) Sad: represents sadness about specific action or event, also it reflects the refusal of the post.

f) Angry: represents the disliking of the post or comment.

Figure 1 demonstrates the well-known Facebook reactions: 


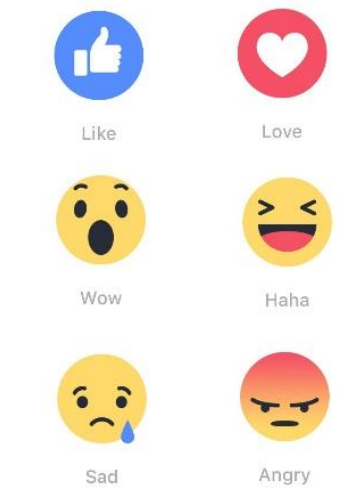

Fig. 1. Facebook Reactions [24].

These emotions have different polarity [25] [14] [26], they are either positive $(+1)$, negative $(-1)$, or idle $(0)$, and these emotions are classified according to their polarity. The following is a classification for the emotions:

a) Like: the default response which indicates that the post is seen, ( 0 polarity).

b) Love: a positive response which indicates that the reader admire the post contents, ( +1 polarity).

c) Wow: a positive response which expresses the reader finds the post interesting, ( +1 polarity).

d) Haha: a positive response which expresses that the reader finds the post funny, (+1 polarity).

e) Sad: a positive response which represents the reader sadness for the post contents, (-1 polarity).

f) Angry: a positive response which expresses the negative effect on the reader from the post contents, (-1 polarity).

\section{B. Vector Space Model}

Different algorithms have been proposed [27] [28] [29], however, Vector space model (VSM) is one of the most popular and successful. VSM contributes to an algebraic model that is able to provide a vector representation to the text document. VSM is popularly applied for index terms extraction, documents indexing, and documents ranking [19]. Measuring text documents similarity is applied using similarity measures such as cosine similarity [30] [31] , Euclidian distance [32].

\section{Sentiment Analysis}

Sentiment Analysis refers to the process of analyzing a document [21] which focus on a determined topic such as a situation or a product and classify the type of document according to the owner's attitude, either he likes or dislikes this document content with respect to the strength level of this attitude.

Text emotion classification methods have been demonstrated in different research with a filtration approach such as in data [33] [34]. Sentiment analysis could be performed using different approaches such as Sentiment Identification Algorithm which is Compositional Semantic Rule, Numeric Sentiment Identification, Vector space model, and Bag-of-Word and Rule-based. All these algorithms are used in Machine Learning Model which involves several classifiers such as Decision Tree, Random Forest, Logistic Correlation and Neural Network. [25].

\section{Correlation Analysis}

Correlation approach measures the degree that two variables are supporting each other [35]. The correlation coefficient measures how much a variable has an impact in changing the other variable performance and is able to change its value.

- A correlation coefficient is +1 when the increase of the variable leads to a fixed proportion increase positively to the dependent variable.

- A correlation coefficient is -1 when the increase of the variable leads to a to a fixed proportion decrease to the dependent variable.

- A correlation coefficient is 0 indicates that the two variables have no relation and there is no impact of one to the other.

\section{PROPOSED MODEL}

The proposed model follows the previously discussed techniques for measuring the post credibility [36] [37], this section demonstrates how these techniques are correlated and reformed in a homogenous model to support the required target. The proposed model is divided into three main phases as follows:

\section{A. Preprocessing Comment Text}

The text preprocessing is processed through several steps: [26] [20] [38].

\section{Step 1:Spelling check}

One of the main steps is performing a spelling check as preliminary step to avoid errors in the following phases. This step requires a dictionary that contains expressions in different forms like verbs, adjectives, nouns, etc.

\section{Step 2: Text Preprocessing}

This step aims to perform a tokenization process or text normalization. It includes eliminating white space and punctuations, Stemming, stop word removal and case folding by transforming the capital letter to lower case.

\section{Step 3:Part of Speech Tagging}

Part-of-Speech Tagging targets to read the text in a specific language and assign a tag to each token to define its type such as nouns, verbs, adjectives, etc.

\section{Step 4:Building Vector}

In this step, the extracted tokens are stored as a vector. This step is preparatory step for applying the vector space model for measuring the sentiment analysis in the next process. As Vector space model depends mainly on the idea of similarity, therefore, cosine similarity measure [8] was selected as it proved to be efficient in the field of sentiment analysis. 


\section{B. Sentiment Analysis of Comment Text}

In this phase, applying sentiment analysis techniques is performed for the main research target. As previously stated, different approaches could be selected according to the document nature, in this research and according to the literature review that is performed by the authors, SVM is the technique that will be applied in the proposed model.

Performing documents classification for the posts' comments is performed using the lexicon approach in [8]. Mohsen and his colleagues developed an opinion lexicon in [8] that contains 6800 words classified as positive or negative. Then applying cosine similarity for the created vectors is performed with measuring the polarity of each as discussed in previous sections.

\section{Calculating the Correlation Coefficient}

The Facebook posts are classified to negative or positive according to post's reactions, and each comment on the post is classified by using sentiment analysis.

For each post, the correlation coefficient value is calculated between the results of classification of reactions and comments, targeting to determine if the classification of comments is similar to the classification reactions.

The correlation coefficient is calculated through the following equations: [21] [39].

$$
r=\frac{1}{n-1}\left[\frac{\sum_{x} \sum_{y}(x-\bar{x})(y-\bar{y})}{S_{x} S_{y}}\right]
$$

The overall results give an indication of the post credibility according to the degree of similarity between comments and reactions.

\section{EXPERIMENTAL RESULTS}

An example for the model process is as follows:

Post A has the values illustrated in table I:

Total number of Negative reactions=

Sad (140) + Angry (195) $=335$

Total number of Positive reactions $=$

Love (91) + Wow (35) + Haha (28) $=154$

Percentage of Negative $=$

$\frac{\text { (Total Number of negative) }}{(\text { Total Number of reactions) }} X 100=68.50$

Percentage of Positive $=$

$\frac{\text { (Total Number of positive) }}{\text { (Total Number of reactions) }} X 100=31.49$

TABLE I. POST'S REACTIONS EXAMPLE

\begin{tabular}{|l|l|l|l|l|l|}
\hline Like & Love & Wow & Haha & Sad & Angry \\
\hline 250 & 91 & 35 & 28 & 140 & 195 \\
\hline
\end{tabular}

Then the post is classified to be Negative
The comment classification is classified according to the vector space model by measuring the similarity. The lexicon contains 6800 words classified as positive or negative with the ability for enrichment as discussed in [8]. Each class is considered as a document, and the comment is also considered as a document. Then the similarity between the comment and each document class, the higher value is the classified class.

For example, a comment state that: "it is a bad product."

After applying text preprocessing, there are two extracted words: bad and product, and the result shown in table II.

These results are calculated for each post as illustrated in table III.

TABLE II. COMMENT ClasSIFICATION EXAMPLE

\begin{tabular}{|l|l|l|l|}
\hline Comment ID & Negative & Positive & Result \\
\hline $1423 \_25$ & 1 & 0 & Positive \\
\hline
\end{tabular}

TABLE III. POST Classification EXAMPLE

\begin{tabular}{|l|l|l|l|}
\hline Post ID & Negative comments & Positive comments & Result \\
\hline 1423 & 258 & 349 & Positive \\
\hline
\end{tabular}

\section{Evaluation}

Although the experimental phase in researches can use benchmark resources [40] [41] [42] [43] [44], however, applying the proposed approach on a real case highly prove the approach effectiveness [45] [46] [47] [48].

The dataset sample followed the research in [49] [50]for selecting the suitable sampling technique. It was collected, like the following:

The research focused on 8 Facebook pages News agencies and 21 posts selected from the Facebook pages shown in table IV.

Each post has a number of comments; a total number of comments in the dataset is $\mathbf{1 5 2 3}$. For each post, we collected the emoji, and the polarity classification is calculated as shown in table V and table VI. For the comments the polarity classification is calculated, fig. 2 shows the distribution of classes for each post, the classes are positive, negative and neutral. The post was classified according to the biggest value of the three classes for the comments.

TABLE IV. FACEBOOK PAGES AND SELECTED POSTS

\begin{tabular}{|l|l|l|}
\hline No & Facebook News Page & Number of selected posts \\
\hline 1 & BBC News & 3 \\
\hline 2 & BBC Family News & 3 \\
\hline 3 & CBS News & 3 \\
\hline 4 & NBC News & 3 \\
\hline 5 & NPR news & 3 \\
\hline 6 & Politico & 2 \\
\hline 7 & NY Daily News & 2 \\
\hline 8 & Democratic Underground & 2 \\
\hline
\end{tabular}


TABLE V. POSTS WITH THEIR EMOJI

\begin{tabular}{|c|c|c|c|c|c|c|c|c|c|c|}
\hline ID & $\begin{array}{l}\text { Facebook } \\
\text { Page_Post ID }\end{array}$ & 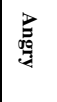 & 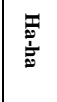 & 謇 & 产 & $\ddot{m}$ & $\stackrel{y}{\sharp}$ & 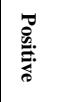 & 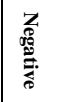 & 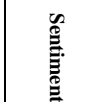 \\
\hline 1 & \begin{tabular}{|l|}
228735667216 \\
10154890879532217
\end{tabular} & 54 & 24 & 993 & 144 & 12 & 24 & 192 & 66 & POSITIVE \\
\hline 2 & \begin{tabular}{|l|}
228735667216 \\
10154890968202217
\end{tabular} & 172 & 8 & 994 & 11 & 783 & 264 & 283 & 955 & NEGATIVE \\
\hline 3 & \begin{tabular}{|l|}
2287356667216 \\
10154890852247217
\end{tabular} & 5 & 12 & 2034 & 369 & 6 & 45 & 426 & 11 & POSITIVE \\
\hline 4 & $\begin{array}{l}228735667216_{-} \\
1426789250735491\end{array}$ & 6 & 0 & 2262 & 754 & 1989 & 11 & 765 & 1995 & NEGATIVE \\
\hline 5 & \begin{tabular}{|l|}
228735667216 \\
10154890645702217
\end{tabular} & 65 & 513 & 4336 & 54 & 128 & 815 & 1382 & 193 & POSITIVE \\
\hline 6 & \begin{tabular}{|l|}
228735667216 \\
10154890600247217
\end{tabular} & 25 & 136 & 2549 & 195 & 2 & 17 & 348 & 27 & POSITIVE \\
\hline 7 & \begin{tabular}{|l|}
228735667216 \\
10154890480662217
\end{tabular} & 0 & 2 & 4123 & 1005 & 2256 & 41 & 1048 & 2256 & NEGATIVE \\
\hline 8 & \begin{tabular}{|l|}
228735667216 \\
10154890399087217
\end{tabular} & 51 & 273 & 1302 & 24 & 39 & 190 & 487 & 90 & POSITIVE \\
\hline 9 & \begin{tabular}{|l|}
228735667216 \\
1887717684813716
\end{tabular} & 403 & 10 & 2169 & 15 & 874 & 115 & 140 & 1277 & NEGATIVE \\
\hline 10 & \begin{tabular}{|l|}
228735667216 \\
10154889414912217
\end{tabular} & 745 & 1 & 1374 & 16 & 722 & 106 & 123 & 1467 & NEGATIVE \\
\hline 11 & \begin{tabular}{|l|}
228735667216 \\
10154889386187217
\end{tabular} & 4 & 8 & 2667 & 195 & 729 & 9 & 212 & 733 & NEGATIVE \\
\hline 12 & \begin{tabular}{|l|}
228735667216 \\
10154889308562217
\end{tabular} & 153 & 7 & 983 & 10 & 323 & 12 & 29 & 476 & NEGATIVE \\
\hline 13 & \begin{tabular}{|l|}
228735667216 \\
10154889223727217
\end{tabular} & 626 & 70 & 747 & 23 & 28 & 25 & 118 & 654 & NEGATIVE \\
\hline 14 & \begin{tabular}{|l|}
2287356667216 \\
10154889016422217
\end{tabular} & 3 & 47 & 11024 & 1120 & 24 & 2531 & 3698 & 27 & POSITIVE \\
\hline 15 & \begin{tabular}{|l|}
228735667216 \\
10154888875107217
\end{tabular} & 3 & 1117 & 3488 & 64 & 36 & 602 & 1783 & 39 & POSITIVE \\
\hline 16 & \begin{tabular}{|l|}
228735667216 \\
10154888663672217
\end{tabular} & 2 & 8 & 3644 & 335 & 1 & 59 & 402 & 3 & POSITIVE \\
\hline 17 & \begin{tabular}{|l}
228735667216 \\
10154888522807217
\end{tabular} & 5356 & 4235 & 5455 & 214 & 259 & 1231 & 5680 & 5615 & POSITIVE \\
\hline 18 & \begin{tabular}{|l|}
228735667216 \\
10154888481772217
\end{tabular} & 5886 & 253 & 8299 & 163 & 948 & 1440 & 1856 & 6834 & NEGATIVE \\
\hline 19 & \begin{tabular}{|l}
$228735667216_{-}$ \\
10154888328917217
\end{tabular} & 289 & 34 & 1075 & 52 & 13 & 36 & 122 & 302 & NEGATIVE \\
\hline 20 & \begin{tabular}{|l}
228735667216 \\
10156521638374968
\end{tabular} & 2 & 75 & 811 & 17 & 23 & 231 & 323 & 25 & POSITIVE \\
\hline 21 & \begin{tabular}{|l|}
228735667216 \\
10155178616101971
\end{tabular} & 285 & 3941 & 11194 & 175 & 66 & 4830 & 8946 & 351 & POSITIVE \\
\hline
\end{tabular}

TABLE VI. POST'S COMMENTS WITH THEIR SENTIMENT ANALYSIS

\begin{tabular}{|l|l|l|l|}
\hline ID & $\begin{array}{l}\text { Facebook Page } \\
\text { Post ID }\end{array}$ & message & Sentiment \\
\hline 1 & $\begin{array}{l}228735667216 \\
10154890879532217\end{array}$ & $\begin{array}{l}\text { We are speaking to NRA supporters as well as } \\
\text { Women's March supporters }\end{array}$ & POSITIVE \\
\hline 2 & $\begin{array}{l}228735667216- \\
10154890879532217\end{array}$ & $\begin{array}{l}\text { If you are just joining us, we are outside of the } \\
\text { headquarters of the National Rifle Association } \\
\text { outside of Washington DC. The Women's March } \\
\text { are demonstrating and then marching to the } \\
\text { Department of Justice to protest a controversial } \\
\text { commercial. }\end{array}$ & NEGATIVE \\
\hline 3 & $\begin{array}{l}228735667216- \\
10154890879532217\end{array}$ & $\begin{array}{l}\text { Do you know how backward America is in } \\
\text { allowing people to have guns? Nineteen kids per } \\
\text { day die in the USA by accidental shootings... } \\
\text { Constitutional rights! Get a grip. }\end{array}$ & NEGATIVE \\
\hline 4 & $\begin{array}{l}228735667216- \\
10154890879532217\end{array}$ & $\begin{array}{l}\text { People who legally own guns often seem all too } \\
\text { eager for an opportunity to shoot someone. } \\
\text { Statistics show that guns bought 'for protection' } \\
\text { very rarely get used as intended. Ask any ER } \\
\text { doctor. }\end{array}$ & NEGATIVE \\
\hline
\end{tabular}

\section{Post ID:228735667216_10154888328917217}

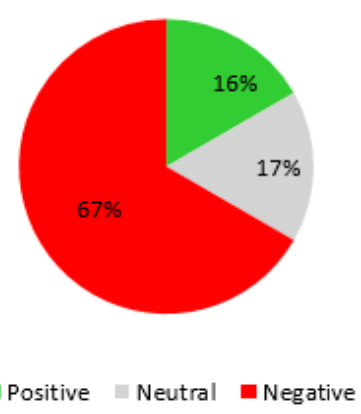

Fig. 2. Pie Chart of Post's Comments Classification.

Table VII shows the posts polarity according to their comments for the specific Facebook page. The final step targets to calculate the credibility score by measuring the correlation coefficient between the Facebook emoji reactions on the post and the polarity of the comments on the same post, the degree of matching between the emoji reactions and polarity of comments represents the degree of credibility of Facebook post as shown in table VIII.

TABLE VII. FACEBOOK PAGE'S COMMENTS POLARITY

\begin{tabular}{|l|l|l|l|l|}
\hline ID & $\begin{array}{l}\text { Facebook Page } \\
\text { Post ID }\end{array}$ & Positive & Negative & Sentiment \\
\hline 1 & $\begin{array}{l}228735667216_{-} \\
10154888328917217\end{array}$ & 2 & 8 & NEGATIVE \\
\hline 2 & $\begin{array}{l}228735667216_{-} \\
10154888481772217\end{array}$ & 8 & 8 & NEGATIVE \\
\hline 3 & $\begin{array}{l}228735667216_{-} \\
10154888522807217\end{array}$ & 16 & 8 & POSITIVE \\
\hline 4 & $\begin{array}{l}228735667216_{-} \\
10154888663672217\end{array}$ & 54 & 18 & POSITIVE \\
\hline 5 & $\begin{array}{l}228735667216_{-} \\
10154888875107217\end{array}$ & 58 & 38 & POSITIVE \\
\hline 6 & $\begin{array}{l}228735667216_{-} \\
10154889016422217\end{array}$ & 72 & 26 & POSITIVE \\
\hline 7 & $\begin{array}{l}228735667216_{-} \\
10154889223727217\end{array}$ & 8 & 12 & NEGATIVE \\
\hline 8 & $\begin{array}{l}228735667216_{-} \\
10154889308562217\end{array}$ & 40 & 30 & POSITIVE \\
\hline 9 & $\begin{array}{l}228735667216_{-} \\
10154889386187217\end{array}$ & 26 & 8 & POSITIVE \\
\hline 10 & $\begin{array}{l}228735667216_{-} \\
10154889414912217\end{array}$ & 16 & 46 & NEGATIVE \\
\hline 11 & $\begin{array}{l}228735667216_{-} \\
10154890399087217\end{array}$ & 44 & 42 & POSITIVE \\
\hline 12 & $\begin{array}{l}228735667216_{-} \\
10154890480662217\end{array}$ & 63 & 30 & POSITIVE \\
\hline 13 & $\begin{array}{l}228735667216_{-} \\
10154890600247217\end{array}$ & 35 & 47 & NEGATIVE \\
\hline 14 & $\begin{array}{l}228735667216_{-} \\
10154890645702217\end{array}$ & 44 & 43 & POSITIVE \\
\hline 15 & $\begin{array}{l}228735667216_{-} \\
10154890852247217\end{array}$ & 66 & 12 & POSITIVE \\
\hline 16 & $\begin{array}{l}228735667216_{-} \\
10154890879532217\end{array}$ & 31 & 50 & NEGATIVE \\
\hline 17 & $\begin{array}{l}228735667216_{-} \\
10154890968202217\end{array}$ & 27 & 53 & NEGATIVE \\
\hline 18 & $\begin{array}{l}228735667216_{-} \\
10155178616101971\end{array}$ & 6 & 4 & POSITIVE \\
\hline 19 & $\begin{array}{l}228735667216_{-} \\
10156521638374968\end{array}$ & 40 & 34 & POSITIVE \\
\hline
\end{tabular}


The value of negative for the post is replaced with (-1), and the value of positive is replaced with $(+1)$ for calculating the correlation coefficient.

The correlation coefficient for the values in table VIII is calculated to be 0.337099931 .

The correlation coefficient value is between 0 to 1 according to the strength or similarity between the two variables.

The credibility rank of the previous posts for the Facebook page as a percentage is: $0.3371 * 100=33.71 \%$

So the rule extracted from previous calculations is:

The Posts of a Facebook page with ID (228735667216) is $33.71 \%$

After reviewing the presented example with experts, it is confirmed that that the results shown is related to the post status. Therefore, after applying the proposed model to the collected dataset and reviewing the results with an expert, the proposed model is found to have an accuracy of $95 \%$ for detecting the News' credibility. However, more investigation was required for manipulating the abnormality to increase the accuracy.

Credibility percentage increases the share and use of the UGC contents that it is probably credible, and at the same time, it ignores the UGC that it is not probably credible. Many enhancements could be applied to increase the accuracy of the model, like applying deeper data mining or machine learning techniques, which will be our target for future work.

TABLE VIII. FACEBOOK PAGE (228735667216) POSTS' ANALYSIS

\begin{tabular}{|l|l|l|l|l|l|}
\hline ID & Post ID & Emoji & Comment & Emoji & Comment \\
\hline 1 & 10154888328917217 & NEGATIVE & NEGATIVE & -1 & -1 \\
\hline 2 & 10154888481772217 & NEGATIVE & NEGATIVE & -1 & -1 \\
\hline 3 & 10154888522807217 & POSITIVE & POSITIVE & 1 & 1 \\
\hline 4 & 10154888663672217 & POSITIVE & POSITIVE & 1 & 1 \\
\hline 5 & 10154888875107217 & POSITIVE & POSITIVE & 1 & 1 \\
\hline 6 & 10154889016422217 & POSITIVE & POSITIVE & 1 & 1 \\
\hline 7 & 10154889223727217 & NEGATIVE & NEGATIVE & -1 & -1 \\
\hline 8 & 10154889308562217 & NEGATIVE & POSITIVE & -1 & 1 \\
\hline 10 & 10154889414912217 & NEGATIVE & NEGATIVE & -1 & -1 \\
\hline 11 & 10154890399087217 & POSITIVE & POSITIVE & 1 & 1 \\
\hline 12 & 10154890480662217 & NEGATIVE & POSITIVE & -1 & 1 \\
\hline 13 & 10154890600247217 & POSITIVE & NEGATIVE & 1 & -1 \\
\hline 14 & 10154890645702217 & POSITIVE & POSITIVE & 1 & 1 \\
\hline 15 & 10154890852247217 & POSITIVE & POSITIVE & 1 & 1 \\
\hline 16 & 10154890879532217 & POSITIVE & NEGATIVE & 1 & -1 \\
\hline 17 & 10154890968202217 & NEGATIVE & NEGATIVE & -1 & -1 \\
\hline 18 & 10155178616101971 & POSITIVE & POSITIVE & 1 & 1 \\
\hline 20 & 1426789250735491 & NEGATIVE & POSITIVE & -1 & 1 \\
\hline 21 & 1887717684813716 & NEGATIVE & POSITIVE & -1 & 1 \\
\hline
\end{tabular}

\section{CONCLUSION AND FutuRE DIRECTIONS}

Social Network is a main source of News which leads to the extreme importance for these sources. However, it is a fact that it is also considered a gate to rumors. The users' reaction is a central factor for spreading the News either it is real of Fake. Therefore, this research focused on measuring the News' credibility in Social media in general and on Facebook in specific. The proposed model was based on three main pillars, an enrichment sentiment lexicon approach, a sentiment analysis approach, and determining correlations. The proposed model considered both the users comments and emotions. The main idea was relating the post contents with the users' response. The results showed the success of the proposed model, however, it only included text comments, and it needs to include other types of comments including images. Moreover, the paper only included English language, therefore, including multilingual component to the proposed approach is one of the key factors in the future directions. A future direction was to improve the accuracy level by considering an enhancement to the SVM approach as well as including the users' trend in their reactions by applying a semantic network that relates between the News networks with the users' network.

\section{ACKNOWLEDGEMENT}

The authors would like to express their sincerest gratitude to Prof. Ayman E. Khedr who was leading all the research stages and provided insight and invaluably expertise that greatly assisted the research.

\section{REFERENCES}

[1] Azhary, A. M. Idrees and A. Rafea, "Diagnostic expert system using non monotonic reasoning," Expert Systems with Applications, vol. 23, no. 2, 2002.

[2] M. Hazman and A. M. Idrees, "A healthy nutrition expert system for," in E-Health and Bioengineering Conference (EHB), 2015.

[3] A. E. Khedr, M. Kadry and G. Walid, "Proposed framework for implementing data mining techniques to enhance decisions in agriculture sector Applied case on Food Security Information Center Ministry of Agriculture," 2015.

[4] A. Mostafa, A. E. Khedr and A. Abdo, "Advising Approach to Enhance Students' Performance Level in Higher Education Environments," Journal of Computer Science, vol. 13, no. 5, pp. 130-139, 2017.

[5] A. E. Khedr, S. A. Kholeif and S. H. Hessen, "Adoption of cloud computing framework in higher education to enhance educational process," International Journal of Innovative Research in Computer Science and Technology (IJIRCST), vol. 3, no. 3, pp. Pp. $150-156$, March 2015.

[6] A. E. Khedr, S. A. Kholeif and S. H. Hessen, "Enhanced Cloud Computing Framework to Improve the Educational Process in Higher Education: A case study of Helwan University in Egypt," International Journal of Computers \& Technology (IJCT), Volume 14, No. 6, pp. 5814 - 5823, April 2015.

[7] A. E. Khedr, A. M. Idrees, A. E.-F. Hegazy and S. El-Shewy, "A proposed configurable approach for recommendation systems via data mining techniques," Enterprise Information Systems, 2017.

[8] A. M. Mohsen, H. A. Hassan and A. M. Idrees, "A Proposed Approach for Emotion Lexicon Enrichment.," International Journal of Computer, Electrical, Automation, Control and Information Engineering, vol. 10, no. 1, 2016.

[9] A. M. Mohsen, H. A. Hassan and A. M. Idrees, "Documents Emotions Classification Model Based on TF IDF Weighting," International Journal of Computer Electrical Automation Control and Information Engineering, vol. 10, no. 1, 2016. 
[10] A. E. Khedr and A. M. Idrees, "Enhanced e-Learning System for eCourses Based on Cloud Computing," Journal of Computers, vol. 12, no. 1, 2017.

[11] T. A. Pempek, Y. A. Yevdokiya and C. L. Sandra, "College students' social networking experiences on Facebook," Journal of applied developmental psychology, vol. 30, no. 3, pp. 227-238, 2009.

[12] R. Hanna, A. Rohm and V. L. Crittenden, "We're all connected: The power of the social media ecosystem," Business horizons, vol. 54, no. 3, pp. 265-273, 2011.

[13] J. Paliszkiewicz \& A.Koohang, Social Media and Trust: A Multinational Study of University Students, Informing Science Press, 2016.

[14] M. Othman, H. Hassan, R. Moawad and A. M. Idrees, "A Linguistic Approach for Opinionated Documents Summary," Future Computing and Informatics Journal, vol. 3, no. 2, pp. 152-158, 2018.

[15] M. A. Abdel-Fattah, A. E. Khedr and Y. Nagm Aldeen, "An Evaluation Framework for Business Process Modeling Techniques," International Journal of Computer Science and Information Security (IJCSIS), vol. 15, no. 5, pp. 382-392, 2017.

[16] T. Sarah and S. Jenkins, "Why Facebook Reactions are good news for evaluating social media campaigns," Journal of Direct, Data and Digital Marketing Practice, vol. 17, no. 3, 2016.

[17] I. Badache and M. Boughanem, "Emotional Social Signals for Search Ranking," in the 40th International ACM SIGIR Conference, SIGIR '17, 2017.

[18] F. K. Alsheref, "Applying emotions in social network connections," International Journal of Web Based Communities, vol. 13, no. 4, 2017.

[19] G. Salton, A. Wong and C. S. Yang, "A vector space model for automatic indexing," Communications of the ACM, vol. 18, no. 11, pp. 613-620.

[20] H. A. Hassan, M. Y. Dahab, K. Bahnasy and A. M. Idrees, "Arabic Documents Classification Method a Step towards Efficient Documents Summarization," International Journal on Recent and Innovation Trends in Computing and Communication, vol. 3, no. 1, pp. 351-359, 2015.

[21] A. L. Maas, R. E. Daly, P. T. Pham, D. Huang, A. Y. Ng and C. Potts, "Learning Word Vectors for Sentiment Analysis," in Proceedings of the 49th annual meeting of the association for computational, 2011.

[22] A. E. Khedr, S. Kholeif and F. Saad, "An Integrated Business Intelligence Framework for Healthcare Analytics," International Journal of Advanced Research in Computer Science and Software Engineering, vol. 7, no. 5, pp. 263-270, 2017.

[23] S. Volkova, Y. Bachrach, M. Armstrong and V. Sharma, "Inferring Latent User Properties from Texts," in Proceeding of AAAI'15 Proceedings of the Twenty-Ninth AAAI Conference on Artificial Intelligence, 2015.

[24] Y. Tian, T. Galery, G. Dulcinati, E. Molimpakis and C. Sun, "Facebook Sentiment: Reactions and Emojis," in Proceedings of the Fifth International Workshop on Natural Language Processing for Social Media, 2017.

[25] C. Whitelaw, N. Garg and S. Argamon, "Using appraisal groups for sentiment analysis," in Proceedings of the 14th ACM international conference on Information and knowledge management, 2005.

[26] M. Othman, H. Hassan, R. Moawad and A. M. Idrees, "Using NLP Approach for Opinion Types Classifier," Journal of Computers, vol. 11, no. 5, pp. 400-410, 2016.

[27] A. E. Khedr, A. I. El Seddawy and A. M. Idrees, "Performance Tuning of K-Mean Clustering Algorithm a Step towards Efficient DSS," International Journal of Innovative Research in Computer Science \& Technology (IJIRCST), vol. 2, no. 6, pp. 111-118, 2014.

[28] A. E. Khedr, A. . M. Idrees and A. Elseddawy, "Enhancing Iterative Dichotomiser 3 algorithm for classificat decision tree," WIREs Data Mining and Knowledge Discovery, vol. 6, 2016.

[29] A. E. Khedr and A. I. El Seddawy, "A Proposed Data Mining Framework for Higher Education System," International Journal of Computer Applications, vol. 113, no. 7, pp. 24-31, 2015.

[30] A. B. El Seddawy, T. Sultan and A. E. Khedr, "Enhanced K-mean Algorithm to Improve Decision Support System under Uncertain Situations," IJCSNS International Journal of Computer Science and Network Security, vol. 13, no. 7, 2013.
[31] M. Y. Dahab, A. M. Idrees, H. A. Hassan and A. Rafea, "Pattern Based Concept Extraction for Arabic Documents," International Journal of Intelligent Computing and Information Sciences, vol. 10, no. 2, 2010.

[32] M. Sayed, R. Salem and A. E. Khedr, "A Survey of Arabic Text Classification Approaches," International Journal of Computer Applications in Technology, vol. 95, no. 3, pp. 236-251, 2019.

[33] A. E. Khedr and A. M. Idrees, "Adapting Load Balancing Techniques for Improving the Performance of e-Learning Educational Process," Journal of Computers, vol. 12, no. 3, pp. 250-257, 2017.

[34] A. E. Khedr, M. A. Abdel-Fattah and Y. Nagm-Aldeen, "A Literature Review of Business Process Modeling Techniques," International Journal of Advanced Research in Computer Science and Software Engineering, vol. 5, no. 3, pp. 43-47, 2015.

[35] H. A. Hassan, M. Y. Dahab, K. Bahnasy, A. M. Idrees and F. Gamal, "Query answering approach based on document summarization," International Open Access Journal of Modern Engineering Research, vol. 4, no. 12, 2014.

[36] Hegazy, Abdel Fatah; Khedr, Ayman E.; Al Geddawy, Yasser;, "An Adaptive Framework for Applying Cloud Computing In Virtual Learning Environment at Education aCase Study of "AASTMT"," in International Conference on Communication, Management and Information Technology (ICCMIT 2015), 2015.

[37] M. M. Nazier, A. E. Khedr and M. Haggag, "Business Intelligence and its role to enhance Corporate Performance Management," International Journal of Management \& Information Technology, vol. 3, no. 3, 2013.

[38] M. Gary, J. Elder and T. Hill, Practical text mining and statistical analysis for non-structured text data applications, Academic Press, 2012.

[39] R. J. Allemang and D. L. Brown, "A correlation coefficient for modal vector analysis," in Proceedings of the 1st international modal analysis conference, 1982.

[40] A. M. Idrees, M. H. Ibrahim and A. I. El Seddawy, "Applying spatial intelligence for decision support systems," Future Computing and Informatics Journal, vol. 3, p. 384e390, 2018.

[41] A. M. Idrees and S. Taie, "Online Price Recommendation System for Shopping Used Cell Phones," Research Journal of Applied Sciences, Engineering and Technology, vol. 13, no. 1, pp. 15-23, 2016.

[42] S. A. Taie and A. M. Idrees, "A Prototype for Breast Cancer Detection and Development Probability Expert System - Towards a Supportive Tool," in The 5th IEEE International Conference on E-Health and Bioengineering - EHB 2015, 215.

[43] A. M. Idrees, "Towards an Automated Evaluation Approach for EProcurement," in 2015 13th International Conference on ICT and Knowledge Engineering (ICT \& Knowledge Engineering 2015), 2015.

[44] A. M. Idrees and A. B. Ibrahim, "Enhancing information technology services for e-business-the road towards optimization," in 13th International Conference on ICT and Knowledge Engineering (ICT \& Knowledge Engineering 2015), 2015.

[45] A. E. Khedr, "Towards Three Dimensional Analyses for Applying ELearning Evaluation Model: The Case of E-Learning in Helwan University," IJCSI International Journal of Computer Science Issues, vol. 9, no. 4, pp. 161-166, 2012.

[46] A. M. Idrees and M. H. Ibrahim, "A Proposed Framework Targeting the Enhancement of Students' Performance in Fayoum University," International Journal of Scientific \& Engineering Research, vol. 9, no. $11,2018$.

[47] N. Sultan, A. E. I. A. M. Khedr and S. Kholeif, "Data Mining Approach for Detecting Key Performance Indicators," Journal of Artificial Intelligence, vol. 10, no. 2, pp. 59-65, 2017.

[48] A. E. Khedr, "Business Intelligence framework to support Chronic Liver Disease Treatment," International Journal of Computers \& Technology, vol. 4, no. 2, pp. 307-312, 2013.

[49] H. A. Hassan and A. M. Idrees, "Sampling technique selection framework for knowledge discovery," in The 7th International Conference on Informatics and Systems (INFOS), 2010.

[50] Y. Helmy, A. E. Khedr, S. Kolief and E. Haggag, "An Enhanced Business Intelligence Approach for Increasing Customer Satisfaction Using Mining Techniques," International Journal of Computer Science and Information Security (IJCSIS), vol. 17, no. 4, 2019. 